\title{
Genetic Diversity Analysis of Iranian Improved Rice Cultivars through RAPD Markers
}

\author{
Ghaffar KIANI \\ Department of Agronomy and Plant Breeding, Sari Agricultural Sciences and Natural \\ ResourcesUniversity, P.O. Box: 578, Sari, Iran; ghkiani@gmail.com
}

\begin{abstract}
The aim of this study was to evaluate the genetic diversity of Iranian improved rice varieties. Sixteen rice varieties of particular interest to breeding programs were evaluated by means of random amplified polymorphic DNA (RAPD) technique. The number of amplification products generated by each primer varied from 4 (OPB-04) to 11 (OPD-11) with an average of 8.2 bands per primer. Out of 49 bands, $33(67.35 \%)$ were found to be polymorphic for one or more cultivars ranging from 4 to 9 fragments per primer. The size of amplified fragments ranged between 350 to 1800 bp. Pair-wise Nei and Li's (1979) similarity estimated the range of 0.59 to 0.98 between rice cultivars. Results illustrate the potential of RAPD markers to distinguish improved cultivars at DNA level. The information will facilitate selection of genotypes to serve as parents for effective rice breeding programs in Iran.
\end{abstract}

Keywords: rice, genetic variation, RAPD, cluster analysis, improved cultivars

\section{Introduction}

The development of DNA marker technology has provided an efficient tool to facilitate plant genetic resource conservation and management. Compared to morphological analysis, molecular markers can reveal differences among accessions at DNA level. They represent an opportunity to provide information on the variation that exists in a particular species within a local region as well as among different countries. They serve as a valuable guide for effective collection and use of genetic resources too. Molecular markers provide information that helps in deciding the distinctiveness of species and their ranking according to the number of close relatives and phylogenetic position (Rahman et al., 2007).

Several types of molecular markers are available for evaluating the extent of genetic variation in rice. These include RFLP (Botstein et al., 1980), RAPD (Williams et al., 1990), AFLP (Vos et al., 1995) and SSR (Tautz, 1989). Of these RAPD markers is increasingly being employed in genetic research owing to its speedy process and simplicity (Williams et al., 1990). This technique always allows the examination of genomic variation without prior knowledge of DNA sequences (Hadrys et al., 1992) and is especially useful for unzipping the variations in species with low genetic variability when other techniques such as isozyme analysis fail to reveal differences among the individuals. Moreover, varietal distinctiveness and relativeness can unambiguously be estimated by RAPD fingerprinting in commercially important crops (Thomas et al., 2006). RAPD markers are considered to be unbiased and neutral markers for genetic mapping applications (Michelmore et al., 1991), in population genetics (Haig et al., 1994), taxonomy (Chapco et al., 1992) as well as for genetic diagnostics. RAPD has been used for classification and assessing diversity and relatness of rice genotypes by several groups (Ko et al., 1994; Mackil, 1995; Raghunathachari et al., 2000; Porreca et al., 2001; Rahman et al., 2007; Rabbani et al., 2008).

This study aimed to use RAPD markers to evaluate the genetic variation within a collection of improved rice varieties and to reveal genetic relationships among them for future use in selection, hybridization, biodiversity assessment and conservation of diverse gene pools.

\section{Materials and methods}

\section{Plant materials}

Sixteen cultivars namely 'Neda, 'Hashemi', 'Shiroudi', 'Tabesh,' 'Pouya,' 'Fajr,' 'Khazar,' 'Shafagh,' 'Nemat,' 'Dasht', 'Champa', 'Amol-3', 'Ghaem-1', 'Ghaem-2', 'Ghaem-3' and 'Sepidrood' were used in this study. Seeds were obtained from Rice Research Institute and University of Agriculture Sciences and Natural Resources, Sari, Mazandaran province, Iran. These genotypes were grown in cropping season of 2010 at research farm of the mentioned University.

\section{DNA extraction, PCR reaction and electrophoresis}

DNA was extracted from leaves of rice genotypes as described by Dellaporta et al. (1983). PCR were performed using 15 ten-mer RAPD markers (Cina Gene, Tehran, Iran). A $25 \mu \mathrm{l}$ mixture was prepared for the PCR reaction which containing $50 \mathrm{ng}$ template DNA, $2.5 \mu \mathrm{l}$ of $10 \mathrm{X}$ buf- 
136

fer, $0.3 \mu \mathrm{l}$ of $10 \mathrm{mM}$ dNTPs, $1 \mu \mathrm{l}$ of $50 \mathrm{mM} \mathrm{MgCl}, 1 \mu \mathrm{l}$ of each of the primers, and 1 unit of Taq polymerase. DNA Molecular Weight Marker (100 bp ladder; Roche) was used to estimate PCR fragment size. The PCR reaction was performed at $94^{\circ} \mathrm{C}$ for $5 \mathrm{~min}$; then for 40 cycles of $94^{\circ} \mathrm{C}$ for 1 $\min ; 35^{\circ} \mathrm{C}$ for $1 \mathrm{~min} ; 72^{\circ} \mathrm{C}$ for $2 \mathrm{~min}$ followed by $72^{\circ} \mathrm{C}$ for $10 \mathrm{~min}$. PCR products were fractioned by $1.5 \%$ agarose gel electrophoresis; then stained with ethidium bromide fluoresce under ultraviolet light and photographed.

\section{Data analysis}

RAPD bands were scored visually. Their presence was scored with 1 and absence with 0 , separately for each cultivar and each primer. If a product was present in a genotype, it was designated as ' 1 ' and if absent it was designated as ' 0 '. Estimates of genetic similarity (F) were calculated between all pairs of the cultivars according to $\mathrm{Nei}$ and $\mathrm{Li}$ (1979) based on following formula:

Similarity $(\mathrm{F})=2 \mathrm{Nab} /(\mathrm{Na}+\mathrm{Nb})$

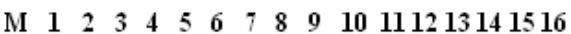
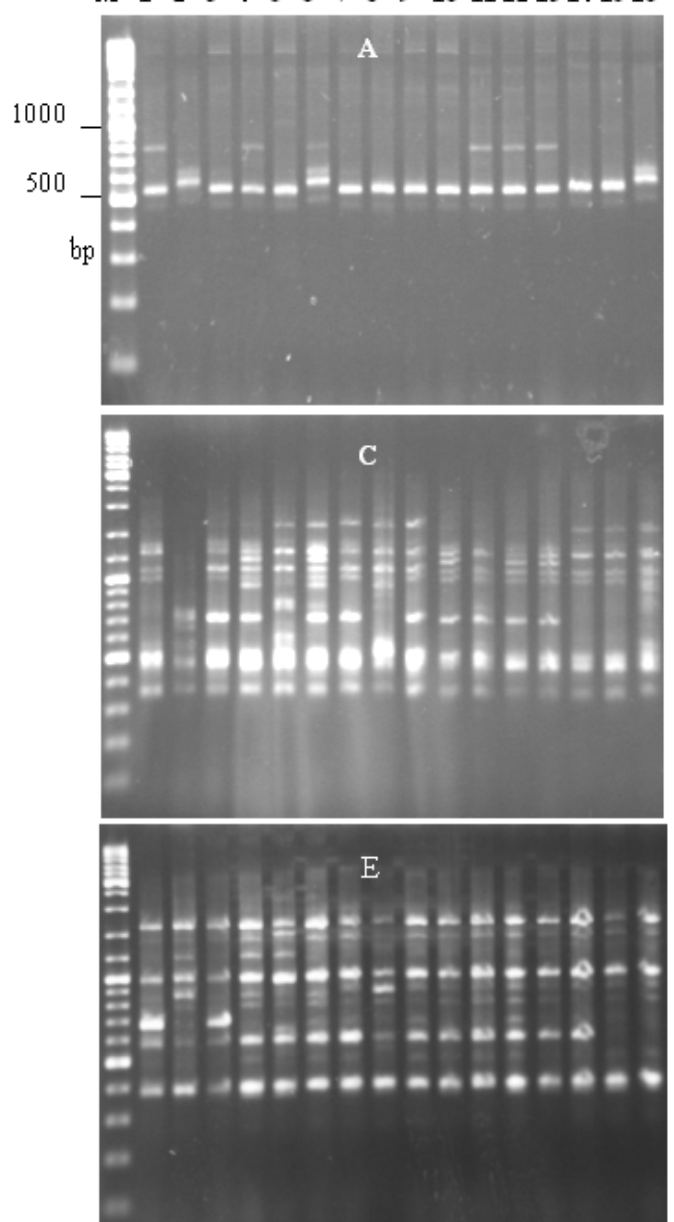

Where $\mathrm{Na}=$ the total number of fragments detected in individual ' $\mathrm{a} ; \mathrm{Nb}=$ the total number of fragments shown by individual ' $b$ ' and $\mathrm{Nab}=$ the number of fragments shared by individuals ' $a$ ' and 'b.' The resulting similarity coefficients were used to evaluate the relationships among cultivars with a cluster analysis using an unweighted pair group method with arithmetic averages (UPGMA). The analysis was plotted in the form of a dendrogram. All computations were carried out using the NTSYS-pc, Version 2.2 package (Rohlf, 1992).

\section{Results}

\section{DNA amplification and polymorphism detection}

The genetic diversity and the relationships among rice genotypes were evaluated by RAPD markers using 15 primers. Out of this, 6 primers that gave rise to amplified products were selected for evaluating genetic relationship of rice cultivars (Tab. 1). Fig. 1 shows the amplification profiles generated with the primers OPB-04, OPA-12,
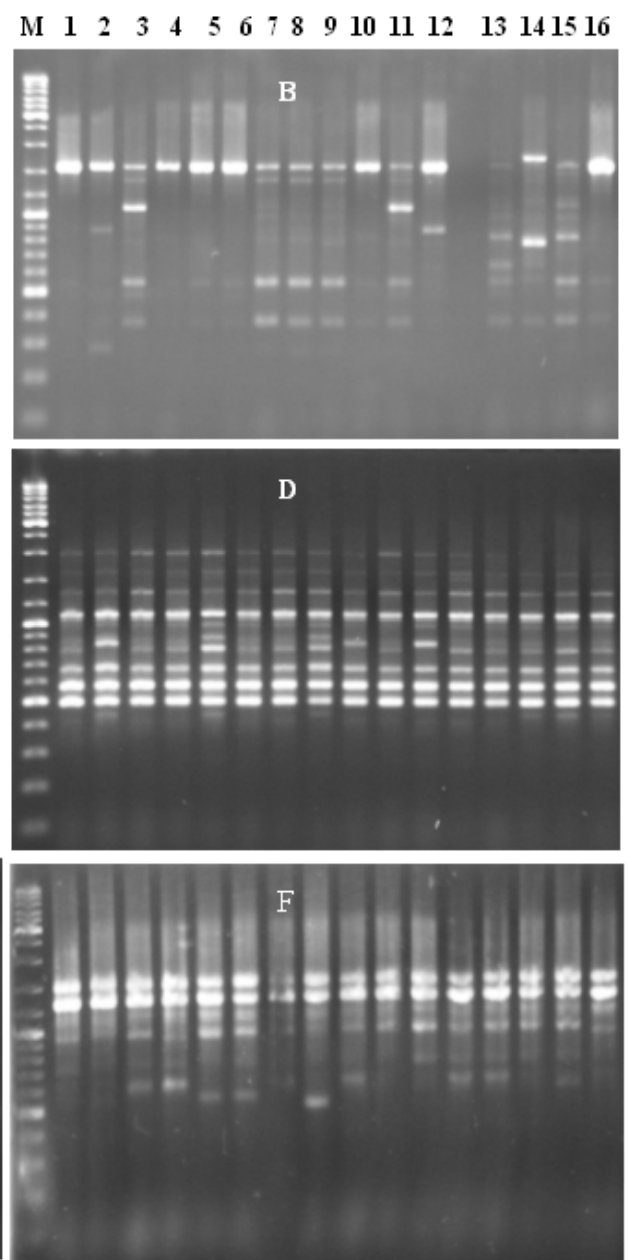

Fig. 1. RAPD profiles of sixteen different cultivars of rice using primer OPB04 (A), OPA-12 (B), OPD-11 (C), OPH-20 (D), OPH-12 (E) and OPA (F). M: Molecular weight marker (100 bp DNA ladder), Lines 1: 'Neda', 2: 'Hashemi', 3: 'Shiroudi', 4: 'Tabesh', 5: 'Pouya, 6: ‘Fajr', 7: 'Khazar', 8: 'Shafagh', 9: 'Nemat', 10: 'Dasht', 11: 'Champa', 12: 'Amol-3', 13: 'Ghaem-1', 14: 'Ghaem-2', 15: ‘Ghaem-3', 16: 'Sepidrood' 
Tab. 1. Primers used for RAPDs in 16 Iranian improved rice cultivars

\begin{tabular}{|c|c|c|c|c|c|}
\hline $\begin{array}{l}\text { こ్ } \\
\text { Z }\end{array}$ & 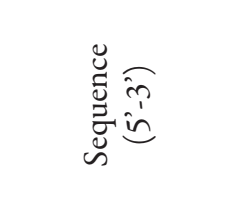 & 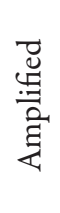 & 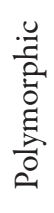 & 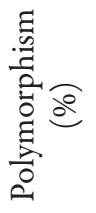 & 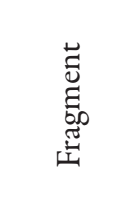 \\
\hline OPA-04 & AATCGGGCTG & 8 & 4 & 50 & $500-1200$ \\
\hline OPA-12 & TCGGCGATAG & 7 & 7 & 100 & $400-1250$ \\
\hline OPB-04 & GGACTGGAGT & 4 & 4 & 100 & $550-1800$ \\
\hline OPD-11 & AGCGCCATTG & 11 & 9 & 81.82 & $350-1250$ \\
\hline OPH-12 & ACGCGCATGT & 9 & 5 & 55.56 & $400-1250$ \\
\hline OPH-20 & GGGAGACATC & 10 & 4 & 40 & $500-1300$ \\
\hline Total & & 49 & 33 & & \\
\hline
\end{tabular}

OPD-11 and OPH-20 across 16 improved cultivars. A considerable level of variability was observed among different cultivars.

A total of 49 reproducible and scorable amplification products were generated across 16 cultivars (Tab. 1) and these were in the size range of 350 to $1800 \mathrm{bp}$. The number of amplification products generated by each primer varied from 4 (OPB-04) to 11 (OPD-11) with an average of 8.2 bands per primer. Out of 49 bands, 33 (67.35\%) were found to be polymorphic for one or more cultivars ranging from 4 to 9 fragments per primer. Primers OPB-04 and OPA-12 gave the highest percentage of polymorphic bands, while the minimum polymorphism was observed using OPH-20 primer.

\section{Similarity matrix}

A similarity matrix based on the proportion of shared RAPD fragments was used to establish the level of relat- edness between improved cultivars. The pairwise Jaccard's coefficients for the genetic similarities among the 16 cultivars are presented in Tab. 2. Relatively high similarity index was observed in 'Ghaem-1' vs 'Ghaem-2', 'Champa' vs 'Amol-3', 'Fajr' vs 'Nemat', 'Shafagh' vs 'Sepidrood' cultivar pairs comparing to the other cultivar pairs. The lowest similarity index were observed in 'Hashemi' vs 'Pouya' (0.59) followed by 'Hashemi' vs either of cultivars 'Neda', 'Champa', 'Amol-3' and 'Ghaem-1' (Tab. 2).

\section{Cluster analysis}

Genetic similarities obtained from RAPD data were used to create a cluster diagram. Cluster analysis based on Nei and Li's (1979) similarity coefficients using UPGMA grouped 16 cultivars into 5 main clusters (Fig. 2) at the similarity coefficient of 0.82 . Cluster I consisted of three sub-clusters and the majority of cultivars were placed in it. In this cluster the coefficient of similarity ranged from 0.73 ('Tabesh' vs 'Sepidrood') to 0.98 ('Ghaem-1'vs 'Ghaem-2') indicating relatively less divergence among the cultivars of this cluster due to originating from closely related ancestors. For example, both 'Ghaem-1' and 'Ghaem-2' developed from the cross between 'Sepidrood' and 'Sange-Jo'. So, it is necessary to avoid crossing between cultivars of this cluster.

The remaining cultivars 'Khazar', 'Ghaem-3', 'Pouya' and 'Hashemi' individually formed next clusters which were more isolated from the other cultivars. Low similarity indices were observed between 'Pouya' and 'Hashemi' (0.59) and among 'Hashemi' with either of cultivars 'Neda', 'Champa', 'Amol-3' with 0.61 similarity index which indicated more divergence. Crossing between the genotypes with low similarity coefficient will manifest high heterosis. As regards to higher quality status of 'Hashemi' among cultivars, it is essential that to pay more attention to it in hybridization programs.

Tab. 2. Similarity matrix for Jaccard's coefficient for 16 rice cultivars based on bands obtained from RAPD markers

\begin{tabular}{|c|c|c|c|c|c|c|c|c|c|c|c|c|c|c|c|c|c|}
\hline No. & Cultivars & 1 & 2 & 3 & 4 & 5 & 6 & 7 & 8 & 9 & 10 & 11 & 12 & 13 & 14 & 15 & 16 \\
\hline 1 & 'Neda' & 1 & & & & & & & & & & & & & & & \\
\hline 2 & 'Hashemi' & 0.61 & 1 & & & & & & & & & & & & & & \\
\hline 3 & 'Shiroudi' & 0.92 & 0.61 & 1 & & & & & & & & & & & & & \\
\hline 4 & 'Tabesh' & 0.78 & 0.63 & 0.82 & 1 & & & & & & & & & & & & \\
\hline 5 & 'Pouya' & 0.73 & 0.59 & 0.73 & 0.80 & 1 & & & & & & & & & & & \\
\hline 6 & 'Fajr' & 0.84 & 0.69 & 0.88 & 0.77 & 0.73 & 1 & & & & & & & & & & \\
\hline 7 & 'Khazar' & 0.71 & 0.69 & 0.67 & 0.65 & 0.61 & 0.75 & 1 & & & & & & & & & \\
\hline 8 & 'Shafagh' & 0.78 & 0.71 & 0.86 & 0.80 & 0.67 & 0.86 & 0.65 & 1 & & & & & & & & \\
\hline 9 & 'Nemat' & 0.82 & 0.71 & 0.86 & 0.84 & 0.75 & 0.94 & 0.77 & 0.84 & 1 & & & & & & & \\
\hline 10 & 'Dasht' & 0.82 & 0.67 & 0.82 & 0.80 & 0.75 & 0.82 & 0.69 & 0.88 & 0.84 & 1 & & & & & & \\
\hline 11 & 'Champa' & 0.84 & 0.61 & 0.88 & 0.86 & 0.77 & 0.84 & 0.67 & 0.86 & 0.86 & 0.86 & 1 & & & & & \\
\hline 12 & 'Amol-3' & 0.84 & 0.61 & 0.88 & 0.90 & 0.77 & 0.84 & 0.67 & 0.86 & 0.90 & 0.90 & 0.96 & 1 & & & & \\
\hline 13 & 'Ghaem-1' & 0.86 & 0.67 & 0.86 & 0.80 & 0.71 & 0.90 & 0.77 & 0.80 & 0.92 & 0.84 & 0.82 & 0.86 & 1 & & & \\
\hline 14 & 'Ghaem-2' & 0.84 & 0.65 & 0.88 & 0.82 & 0.69 & 0.88 & 0.75 & 0.82 & 0.90 & 0.82 & 0.84 & 0.88 & 0.98 & 1 & & \\
\hline 15 & 'Ghaem-3' & 0.78 & 0.75 & 0.73 & 0.71 & 0.75 & 0.82 & 0.77 & 0.71 & 0.84 & 0.71 & 0.69 & 0.73 & 0.88 & 0.86 & 1 & \\
\hline 16 & 'Sepidrood' & 0.84 & 0.69 & 0.84 & 0.73 & 0.65 & 0.84 & 0.67 & 0.94 & 0.82 & 0.86 & 0.80 & 0.80 & 0.82 & 0.80 & 0.73 & 1 \\
\hline
\end{tabular}




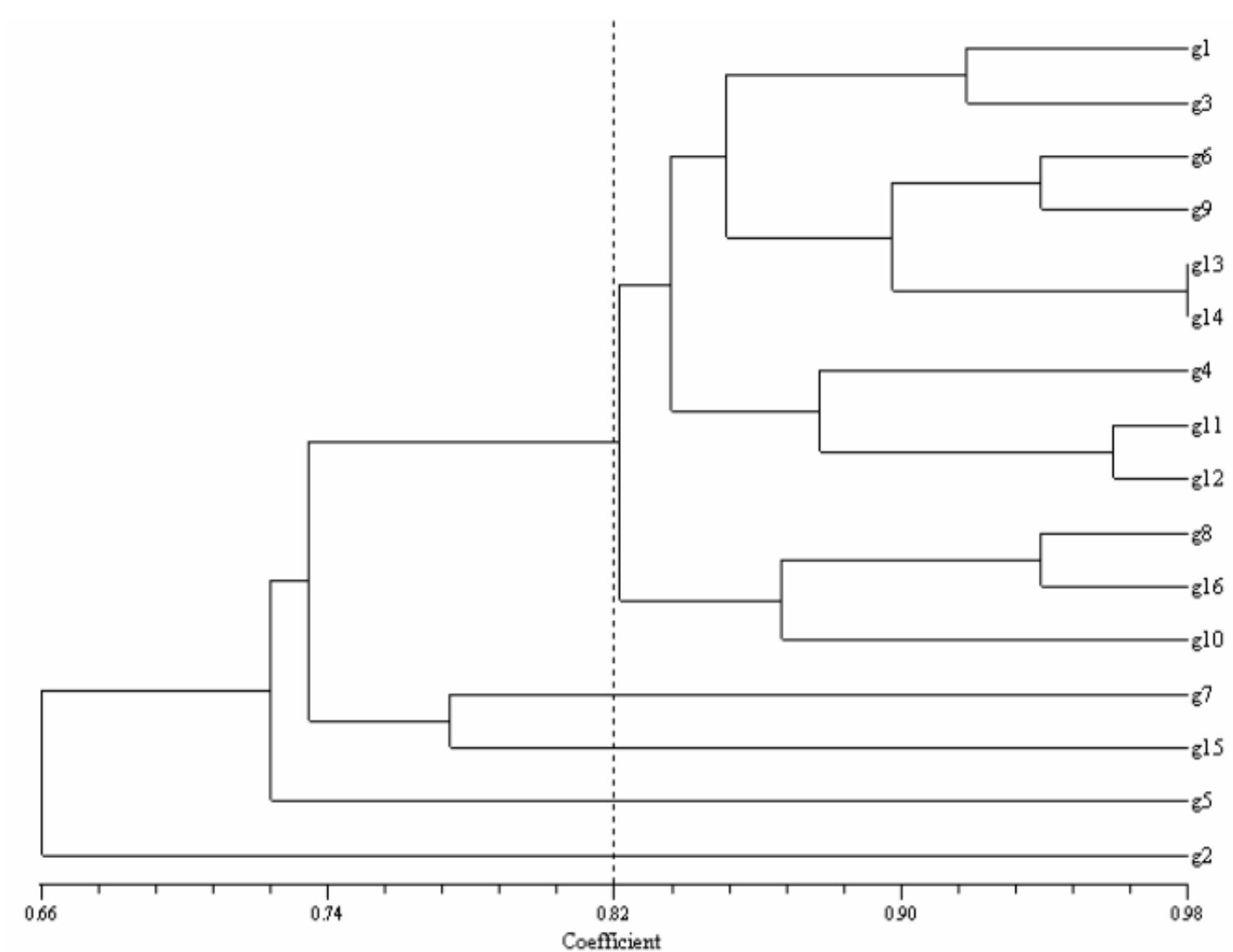

Fig. 2. Dendrogram of improved rice cultivars constructed by cluster analysis of RAPD data. $g_{1}$ : 'Neda', $g_{2}$ :

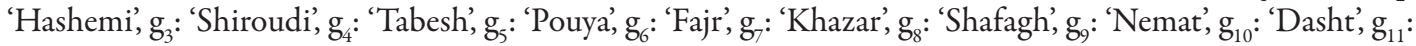

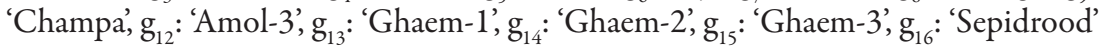

\section{Discussion}

The average number of polymorphic fragments per primer among the 16 rice cultivars was 5.5. This percentage of polymorphic bands was similar to that observed in the study of Choudhury et al. (2001) using RAPD markers. However, the proportion of polymorphic fragments was comparatively lower than those earlier reports using Indian scented basmati and Italian rice cultivars (Porreca et al., 2001; Raghunathachari et al., 2000; Verma et al., 1999). This discrepancy may relate to genotypes and the selection of RAPD primers with scorable bands. The other reason could be the use of more diverse genotypes. In this study, 15 RAPD primers were examined and 6 of them generated scorale bands. In addition, investigated genotypes in this study were chosen from improved cultivars and not from diverse gene pools.

Pair-wise estimates of similarity ranged from 0.59 to 0.98 in this study. Similar values of similarity coefficients were obtained among Pakistani and Indian rice varieties (Davierwala et al., 2000; Ren et al., 2003; Rabbani et al., 2008). In this study analysis on similarity matrix using UPGMA, grouped 16 cultivars into 5 clusters. Studies on genetic diversity and relationships among the different cultivars has been previously reported (Neeraja et al., 2002; Porreca et al., 2001; Rabbani et al., 2008; Saker et al., 2005).
The present work revealed genetic variation and relatedness among the sixteen rice germplasm. The employment of RAPD markers in genetic diversity analysis helped in grouping the genotypes. Cluster analysis based on the RAPD data revealed that genotypes 'Pouya' and 'Hashemi' are clustered in a separate cluster as they have far genetic background from each other and from the rest of the investigated genotypes. In addition, the present study showed that cultivars in first cluster possess high degree of genetic similarity due to originating from closely related ancestors. .

\section{Acknowledgements}

This project (02-1389-02) conducted by financial support of Agricultural Sciences and Natural Resources University, Sari, Iran. Author thank to Dr. M. Sattari and M. Noruzi from Rice Research Institute of Iran for their valuable comments.

\section{References}

Botstein D, White RL, Skolnick M, Davis RW (1980). Construction of genetic linkage map in man using restriction length polymorphisms. Am J Hum Genet 32:314-331.

Chapco W, Ashton NW, Martel RK, Antonishishyn N, Crosby WL (1992). A feasibility study of the use of random 
amplified polymorphic DNA in the population genetics and systemic of grasshoppers. Genome 35:569-574.

Choudhury PR, Kohli S, Srinivasan K Mohapatra T, Sharma RP (2001). Identification and classification of aromatic rices based on DNA fingerprinting. Euphytica 118:243-251.

Davierwala AP, Chowdari KV, Kumar S, Reddy APK, Ranjekar PK, Gupta VS (2000). Use of three different marker systems to estimate genetic diversity of Indian elite rice varieties. Genetica 108:269-284.

Dellaporta SL, Wood J, Hicks JB (1983). A plant DNA minipreparation: version II. Plant Mol Biol Rep 1:19-21.

Hadrys H, Balick M, Schierwater B (1992). Application of random amplified polymorphic DNA (RAPD) in molecular ecology. Mol Ecol 1:55-63.

Haig SM, Rhymer JM, Heckel DG (1994). Population differentiation in randomly amplified polymorphic DNA of red-cockaded woodpeckers Picoides borealis. Mol Ecol 3:581-595.

Ko HI, Cowan DC, Henry RJ, Graham GC, Blakeney AB, Lewin LG (1994). Random amplified polymorphic DNA analysis of Australian rice (Oryza sativa L.) varieties. Euphytica 80:179-189.

Neeraja CN, Sarla N, Siddiq EA (2002). RAPD analysis of genetic diversity in Indian landraces of rice (Oryza sativa $\mathrm{L})$. J Plant Biochem Biotechnol 11:93-97.

Nei M, Li WH (1979). Mathematical model for studying genetic variation in terms of restriction endonucleases. Proc Natl Acad Sci USA 76:5269-5273.

Mackil DJ (1995). Classifying japonica rice cultivars with RAPD markers. Crop Sci 35:889-894.

Michelmore RW, Paran I, Kesseli RV (1991). Identification of markers linked to disease-resistance genes by bulked segregante analysis: A rapid method to detect markers in specific genomic regions by using segregating populations. Proc Natl Acad Sci USA 88:9828-9832.

Porreca P, Sabina MR, Martelli G, Sunseri F, Greco I, Pruneddu G, Spanu A (2001). Genetic variability among Italian rice (Oryza sativa L.) cultivars investigated by RAPDs analysis. J Genet Breed 55:349-355.

Raghunathachari P, Khanna VK, Singh US, Singh NK (2000). RAPD analysis of genetic variability in Indian scented rice germplasm (Oryza sativa L.). Curr Sci 79:994-998.
Rabbani MA, Pervaiz ZH, Masood MS (2008). Geng diversity analysis of traditional and improved cultivars of Pakistani rice (Oryza sativa L.) using RAPD markers. Electron J Biotechnol 11:1-10.

Rahman SN, Islam MDS Alam MDS, Nasiruddin KM (2007). Genetic polymorphism in rice (Oryza sativa L.) through RAPD analysis. Indian J Biotechnol 6:224-229.

Ren F, Lu B, Li S, Huang J, Zhu YA (2003). Comparative study of genetic relationships among the AA genome Oryza species using RAPD and SSR markers. Theor Appl Genet 108:113-120.

Rohlf FJ (1992). NTSYS-pc Numerical Taxonomy and Multivariate Analysis System, Version 1.7. New York, Exeter Publications.

Saker MM, Youssef SS, Abdallah NA, Bashandy HS, Elsharkawy AM (2005). Genetic analysis of some Egyptian rice genotypes using RAPD, SSR and AFLP. Afric J Biotechnol 4:882-890.

Tautz D (1989). Hypervariablity of simple sequences as a general source of polymorphic DNA markers. Nucleic Acids Res 17:6463-6471.

Thomas G, Mohapatra T, Rao AR, Sharma RP (2006). Distinguishing Indian commercial wheat varieties using RAPD based DNA fingerprints. Indian J Biotechnol 5:200206.

Verma SK, Khanna V, Singh N (1999). Random amplified polymorphic DNA analysis of Indian scented basmati rice (Oryza sativa L.) germplasm for identification of variability and duplicate accessions, if any. Electrophoresis 20:17861789.

Vos P, Hogers R, Bleeker M, Reijans M, Van de Lee T, Hornes M, Frijters A, Pot J, Peleman J, Kuiper M (1995). AFLP: a new technique for DNA fingerprinting. Nucleic Acids Res 23:4407-4414.

Williams JGK, Kubelik AR, Livak KJ, Rafalski JA, Scott VT (1990). DNA polymorphisms amplified by arbitrary primers are useful as genetic markers. Nucleic Acids Res 18:65316535. 